\title{
A PERSPECTIVA DIALÓGICA NO AGIR EMPREENDEDOR: UM ESTUDO DE CASO EM UMA LAN HOUSE
}

\author{
Maria Christianni Coutinho Marçal \\ chrismarcal@ hotmail.com \\ Universidade Federal de Pernambuco - Recife, PE/Brasil \\ Sérgio C. Benício de Mello \\ sergio.benicio@pesquisador.cnpq.br \\ Universidade Federal de Pernambuco - Recife, PE/Brasil \\ José Roberto Ferreira Guerra \\ j.roberto.guerra@gmail.com \\ Universidade Federal de Pernambuco - Recife, PE/Brasil \\ Denis Dayvison Soares da Rocha \\ denisrochaufpe@yahoo.com.br \\ Universidade Federal de Pernambuco - Recife, PE/Brasil
}

Recebido em 13/01/2011

Aprovado em 09/05/2012

Disponibilizado em 01/12/2012

Avaliado pelo sistema double blind review

Revista Eletrônica de Administração

Editor: Luís Felipe Nascimento

ISSN 1413-2311 (versão on-line)

Editada pela Escola de Administração da Universidade Federal do Rio Grande do Sul.

Periodicidade: Quadrimestral

Sistema requerido: Adobe Acrobat Reader.

\section{RESUMO}

A tecnocultura é um fenômeno atual e abrangente que age como um mediador entre o homem e o mundo alterando algumas das suas características fundamentais (e.g., as interações sociais, a relação do homem com o tempo/espaço, a construção da subjetividade e a percepção do próprio corpo). Um ambiente de negócios característico desse fenômeno social é a lan house e o objetivo deste artigo é fazer uma modelização do fenômeno empreendedorismo à luz do modelo de Thierry Verstraete (2001) aplicado a esse tipo de negócio. A abordagem integra dois níveis de análise: o empreendedor e a organização impulsionada por ele através do estudo da relação dialógica entre as dimensões que o compõem (cognitiva, praxiológica e estrutural). A metodologia utilizada foi um estudo de caso e a coleta dos dados foi efetuada através de entrevista. Pôde-se concluir que o modelo explorado é abrangente e aborda aspectos fundamentais para a compreensão do fenômeno empreendedorismo. 
A perspectiva dialógica no agir empreendedor: um estudo de caso em uma lan house

Palavras-chave: Tecnocultura; Empreendedorismo; Modelização.

\title{
THE DIALOGIC PERSPECTIVE IN ENTREPRENEUR ACTION: A CASE STUDY IN A LAN HOUSE
}

\begin{abstract}
Technoculture is a contemporary and including phenomenon that acts as a mediador between man and the world modifying some of its fundamental characteristcs (e.g., social interactions, the relation of men with time/space, the subjectivity's construction and the perception of the own body). A typical business environment of this social phenomenon is a lan house and the objective of this article is to modelize the entrepreneurship phenomenom through the Thierry Verstraete (2001)'s theory applied to this kind of business. This approach integrates two levels of analysis: the entrepreneur and the organization through a study of the dialogical relation among three dimensions (cognitive, practical and structural). The methodology used was a case study and the data was collected through interview. It was concluded that the explored model is including and that it contains fundamental aspects to comprehend the entrepreneurship phenomenon.
\end{abstract}

Key-words: Technoculture; Entrepreneurship; Modeling

\section{Introdução}

Vivemos o cotidiano em que a máquina foi substituída pela informação; a fábrica, pelo shopping center; o contato de pessoa a pessoa, pela relação com um vídeo na qual a estética impregna os objetos para que eles se tornem mais atraentes (ROUANET, 1987). Os novos meios de comunicação e tecnologias como multimídia, Internet e realidade virtual proporcionam oportunidades imensas para as empresas conquistarem clientes através de combinações de textos, imagens e vídeos.

Esta é a era da cultura do virtual (LÉVY, 1996; BAUDRILLARD, 1995, 2004; CASTELLS, 1999, 2003), da proliferação de imagens, de sons, da velocidade, da efemeridade, da cibercultura ${ }^{1}$, do ciberpunk $^{2}$, dos videogames e da primazia do consumo de imagens, que, segundo Baudrillard (1995), é um consumo de signos traduzindo-se em simulacros e simulações de situações reais.

Para Baudrillard, o simulacro que faz parte dessa cultura é a realidade "mascarada", imaginada, consentida apenas pelas imagens e representações que fazemos delas, é a hiperrealidade. No que tange a cultura, o simulacro coloca-a como uma esfera de completa autonomia, e nela são jogados os sujeitos descentrados, os quais, devido ao acúmulo de

\footnotetext{
1

Segundo Guimarães, o termo abrange os fenômenos relacionados ao ciberespaço, ou seja, os fenômenos associados às formas de comunicação mediadas por computadores. Por outro lado, Escobar (1994) define o termo como pano de fundo às novíssimas tecnologias, em especial as relacionadas à comunicação digital, à realidade virtual e à biotecnologia.

Termo cunhado por Gardner Dezois para definir o movimento que acreditava que a maior parte da produção da ficção científica estava atrelada a fórmulas concebidas no passado, quando a alta tecnologia ainda não moldava diretamente o cerne da experiência humana. Os escritores que faziam parte desse movimento observaram que a disseminação da tecnologia de ponta, com o avanço da informática, ameaçava tornar a realidade mais estranha e empolgante do que a própria ficção (GIBSON, 2003).
}

REAd I Porto Alegre - Edição 73 - Nº 3 - set/dez 2012 - p. 813-828 
Maria Christianni Coutinho Marçal, Sérgio C. Benício de Mello, José Roberto Ferreira Guerra \& Denis Dayvison Soares da Rocha

imagens e simulações, possuem apenas uma experiência a compartilhar, que é "a alucinação desestabilizada e estetizada da realidade" (BAUDRILLARD, 1995) [grifo nosso].

Segundo Guimarães (1997), esses novos códigos não são completamente inéditos, mas, sim, uma reformulação e uma ressemantização das formas conhecidas de sociabilidade, adaptadas às novas condições, tanto de espaço/tempo virtuais quanto de agentes sociais dinâmicos, cuja capacidade de metamorfose (VELHO, 1994) é levada às últimas consequências. É a confirmação de que cultura não é algo estático, e sim um processo adaptativo, aprendido e incutido (BLACKWELL; ENGELS, 2000).

$\mathrm{O}$ artigo trata da exploração do fenômeno do empreendedorismo inscrito nessa cultura da virtualidade real e na microcultura dos jogadores de videogames. Os números do mercado de games estão crescendo vertiginosamente; já são 110 milhões de jogadores de videogame no mundo com uma média de 26 anos de idade e ainda há quem aposte que os pósadolescentes de hoje continuarão utilizando os consoles e os games até a terceira idade, com programas especiais (RIRBEIRO, 2005). Entre 2003 e 2004, o crescimento do mercado de games no Brasil faturou em torno de 8 milhões de reais, segundo a Abragames (2005); já entre 2007 e 2008, o faturamento da indústria de games foi de 87,5 milhões de reais, segundo a Abragames (2008). Enquanto no ano de 2000, todo o mercado de tecnologia sofreu uma retração devido ao eco do estouro da bolha, o de consoles, softwares e acessórios de videogame cresceu 10\% (ABREU, 2003).

Os games, por um lado, aparecem como instrumentos facilitadores de socialização, aprendizado e comportamento cognitivo, tornando-nos mais aptos a enfrentar a realidade. Por outro lado, aparecem como vilões quando são tachados de "indutores de violência e alienação". De uma forma ou de outra, o que pretendemos mostrar neste trabalho é o papel atribuído ao fenômeno do empreendedorismo inserido na tecnocultura e em uma lan house o locus humano do jogo virtual —, o que nos remeteu à seguinte questão: como a modelização do fenômeno do empreendedorismo de Thierry Verstraete (2001) pode iluminar as práticas de um empreendedor de uma lan house?

\section{Aporte Teórico: O Modelo de Thierry Verstraete}

O crescente interesse pelo tema do empreendedorismo fez surgir duas abordagens que, embora distintas, complementam-se. A primeira equivale à busca pela compreensão do fenômeno segundo uma análise mais "empirizada". A segunda corrente parte de uma análise multidisciplinar, visando levar-se a um melhor entendimento global do tema, conforme as obras do autor que direcionou os estudos deste artigo (VERSTRAETE, 2001, 2002; VERSTRAETE; FAYOLLE, 2005; e VERSTRAETE, 2012).

No Brasil, a preocupação com a criação de empresas e com a redução do alto índice de falência de novos negócios pode ser a razão pela qual o fenômeno empreendedor tenha assumido importância no âmbito do governo, das entidades de classe, de instituições de apoio e da própria academia (FILION, 1999; PREVIDELLI et al., 2001). Vivemos um contexto em que se reconhece a importância do empreendedorismo para o desenvolvimento econômico, ao mesmo tempo que se revela um desconhecimento acerca da pessoa do empreendedor.

Embora não haja consenso entre os teóricos, a inexistência deste é defendida por numerosos autores que reconhecem, como único consenso considerável em sua delimitação semântica e conceitual, o reconhecimento de que não existe consenso (OGBOR, 2000; JULIEN, 2010). Assim, justamente por o empreendedorismo se tratar de um fenômeno de múltiplas manifestações, diversas visões devem ser observadas. Nesse sentido, a proposta é de uma análise que se alie à corrente de entendimento multidisciplinar e, para melhor referenciar

REAd I Porto Alegre - Edição 73 - № 3 - set/dez 2012 - p. 813-828 
A perspectiva dialógica no agir empreendedor: um estudo de caso em uma lan house

o fenômeno empreendedor, descreve-se este como uma prática dialética ligando o criador empreendedor — à criatura - empreendimento (PAIVA JR.; ALMEIDA; GUERRA, 2008).

A proposta defende então a existência de um constante diálogo entre o empreendedor e seu empreendimento. Dessa forma, para se entender o fenômeno empreendedor, não se pode ter a visão única de uma dessas partes, ou mesmo realizar a análise de tais níveis fundamentais isoladamente, uma vez que é justamente da interface simbiótica entre estes que emana a força maior: o fenômeno do empreendedorismo. Assim, busca-se analisar o conjunto de características do empreendedor que influenciam na sua jornada, bem como o modo com que as experiências adquiridas no âmbito do empreendimento contribuem para uma reformulação das características do agente criador, caracterizando o processo dialógico citado (BRUYAT; JULIEN, 2001).

$\mathrm{Na}$ concepção apresentada, a relação dialética pressupõe a existência de três dimensões indissociáveis e irredutíveis entre si. A primeira é a cognitiva, a qual analisa não somente a visão do empreendedor, mas também as suas capacidades reflexivas e de aprendizagem, sem colocar de lado os efeitos das emoções, das motivações, das experiências passadas e da trajetória do indivíduo. A segunda diz respeito à ação e pode ser qualificada de praxiológica. Essa dimensão põe os problemas não somente da imagem da organização impulsionada, mas também aqueles relativos aos múltiplos posicionamentos do empreendedor e da sua organização em cada espaço onde ele se insere. A terceira é estrutural, que corresponde ao contexto da emergência da organização no qual o empreendedor deve se inserir para tentar tornar o ambiente harmonioso com o que ele faz.

Para que se tenha uma visão inicial de como essas dimensões estão correlacionadas no empreendedorismo, observa-se que o empreendedor impulsiona esse fenômeno agindo dimensão praxiológica - dentro da estrutura na qual ele evolui — dimensão estrutural para tentar concretizar e materializar a visão - dimensão cognitiva - que ele tem da organização (VERSTRAETE, 2001).

Ainda em função das dimensões apresentadas, observa-se claramente a constante interação entre os elementos da díade, caracterizando, nesse sentido, o processo como contínuo. Torna-se, ainda, importante que se visualize o empreendedorismo não apenas como o processo de surgimento da organização, cessando sua jornada com o aparecimento desta, pois, na verdade, a essência do fenômeno não está simplesmente na constituição do empreendimento, mas também na maneira como este é conduzido e se relaciona com o meio (VERSTRAETE, 2002).

\section{Dimensão cognitiva}

Verstraete (2001, 2005) define a dimensão cognitiva como o estado cognitivo que leva o indivíduo a contribuir para o conhecimento que gera o empreendimento, bem como a tudo o que levou, por um lado, a gerar esse conhecimento a ele e, por outro lado, a forjar esse estado cognitivo. O estudo desta dimensão é mais bem compreendido através do conhecimento de suas três componentes: o pensamento estratégico, a reflexividade e a aprendizagem, conforme o autor.

$\mathrm{O}$ pensamento estratégico corresponde à visão global que o empreendedor tem da organização. No entanto, tais reflexões constituem-se apenas no plano abstrato, diferindo da dimensão praxiológica por esta estar diretamente associada ao plano de ações e repercutir na modelização do negócio que o empreendedor cria (VERSTRAETE; JOUISON-LAFFITTE, 2007). Nesse sentido, equivale — o pensamento estratégico — à imagem que o agente humano tem da organização, sendo bastante influenciado pela paixão e emoção. Em poucas palavras, equivale à visão de um futuro desejado e realizável para a empresa. 
Maria Christianni Coutinho Marçal, Sérgio C. Benício de Mello, José Roberto Ferreira Guerra \& Denis Dayvison Soares da Rocha

Para a compreensão desse pensamento, o modelo se apoia nas ideias de Karl Weick (1979). Basicamente, o modelo proposto por Weick liga o indivíduo ao fenômeno organizacional, enfatizando a interação entre os esquemas de interpretação do empreendedor e as suas ações. Não que estas últimas sejam o foco da análise, mas que, através de sua análise, seja possível a compreensão de um plano maior e bem-articulado - o pensamento estratégico.

Embora o pensamento estratégico corresponda à visão que se tem da organização, é através da dimensão praxiológica que melhor se podem visualizar as habilidades do empreendedor de aprender e reagir frente aos efeitos causados por suas ações, uma vez que estes, muitas vezes, não são intencionados inicialmente. Assim, o criador aprende na ação de organizar e na estruturação que ele empreende através do processo reflexivo, conforme destacado por Vertraete (2005).

A aprendizagem resulta das experiências passadas e em curso, dos conhecimentos, das predisposições, das situações e das influências sofridas pelas paixões, pelas emoções, pelas motivações, além das faculdades de aprendizagem intrínsecas ao indivíduo. Nesse contexto, o próprio processo de aprendizagem pode variar em função das diferenças individuais, além de distinguir-se o treinamento em áreas simples do treinamento em áreas mais complexas no mundo organizacional (ARGYRIS; SCHÖN, 1988).

Em relação à tríade formada pela visão estratégica, reflexividade e aprendizagem, defende-se que esta também seja indissociável. A sua combinação conduz à "visão empreendedora" do indivíduo, como observado por Verstraete e Jouison-Laffitte (2010). Isso pode ser definido como uma representação do que o empreendedor faz da organização que ele impulsiona, correspondendo à articulação dos esquemas cognitivos relativos ao futuro desejado (dimensão estratégica), à realidade que ele confronta (reflexividade) e aos seus conhecimentos (aprendizagem e predisposição).

\section{A dimensão estrutural}

A dimensão estrutural corresponde ao contexto organizacional no qual o empreendedor se insere e o qual procura tornar mais harmonioso na busca do desenvolvimento de seus planos na organização (VERSTRAETE, 2001, 2005). Segundo a análise de estrutura, diversos modelos poderiam fornecer subsídios ao entendimento desta dimensão. O modelo apresentado por Verstraete adota os trabalhos de Berger e Luckman (1986) e os de Bourdieu (2004). Os primeiros autores abordam a estrutura subjetiva, e Bourdieu apresenta a estrutura objetiva da dimensão.

A estrutura constitui um arranjo particular que permite a um observador ver as ordens e desordens inerentes ao sistema num dado momento. Quando esse observador é um empreendedor potencial, ele pode identificar, na sua estrutura socioeconômica, uma oportunidade de inserção que lhe permita satisfazer à demanda observada. Essa inserção é composta de duas dimensões irredutíveis e indissociáveis: a estrutura objetiva e a estrutura subjetiva.

Bourdieu (2004), ao apresentar a estrutura objetiva, defende que esta se situa na gênese social como produto da existência do homem como ser ontológico e social. No entanto, alguns elementos acabam por exercer forte influência sobre os atores sociais de um determinado grupo de modo a divergirem entre si na sua visão de mundo. Surgem, assim, diferentes "pontos de vista".

$\mathrm{O}$ primeiro elemento apresentado por Bourdieu equivale à posição ocupada pelo indivíduo no grupo, o segundo faz referência à estrutura de capitais inerentes a cada ator do grupo. Esses elementos atuam como um mecanismo dissociativo entre a gênese social e as características individuais.

REAd I Porto Alegre - Edição 73 - No 3 - set/dez 2012 - p. 813-828 
A perspectiva dialógica no agir empreendedor: um estudo de caso em uma lan house

Os tipos de capitais citados são o capital econômico (liquidez, bens possuídos, etc.); o capital cultural, que compreende o capital cultural "incorporado" (hábitos), o capital cultural "objetivo" (bens culturais possuídos, quadros, abras literárias, etc.) e o capital cultural "institucionalizado" (formas de tipos escolares). Somam-se a estes o capital social (rede de relações) e, por fim, o capital simbólico (prestígio, reputação que é dada em uma área). Dessa forma, a trajetória individual, "história de vida", não é neutra sobre o desejo de empreender, podendo-se afirmar que as pessoas têm evoluído no meio empreendedor (PAILOT, 2000).

Por sua vez, a segunda estrutura é produto da subjetividade individual ou coletiva. Quando ela é coletiva, a subjetividade torna-se "objetivante". Defende-se basicamente que os indivíduos erguem fronteiras artificiais cercando os ambientes a fim de lhes conferir uma relativa inteligibilidade. Esta consagra a existência de um universo simbólico compreendendo as convenções (ORLÈAN, 1994, SALAIS, 1994; GOMES, 1994) e as representações sociais (DOISES; PLAMONARI, 1996; JODELET, 1989; ABRIC, 1994; GUIMELLI, 1994).

As convenções são mencionadas como regras mais ou menos explícitas às quais um sujeito adere eventualmente, tendo certeza da adesão de outros atores a essas regras, ainda que inconsciente, voluntária ou involuntariamente, podendo responder a um simples fenômeno de adaptação. As representações sociais, por sua vez, equivalem às representações compartilhadas de certos objetos dentro de um espaço social e são adquiridas pelo indivíduo quando há a imersão duradoura deste em determinado espaço. Dessa forma, não existe um princípio de adesão ou de escolha. Mais do que adaptação, é a noção de socialização que seria utilizada nessa perspectiva, estabelecendo uma ação dialética entre os pares envolvidos no empreendimento (VERSTRAETE, 2000).

A combinação dessas teorias permite compreender não apenas os aspectos da socialização empreendedora, como também suas consequências, destacando-se a capacidade de tomar decisões no processo de persuasão de seus stakeholders.

\section{A dimensão praxiológica}

A dimensão praxiológica constitui a essência da materialização e da concretização do fenômeno empreendedor. Equivale à interface de comunicação efetiva com o meio através de ações. Dois tipos de ações servem ao fenômeno empreendedor: o posicionamento e a geração de uma configuração organizacional (VERSTRAETE 2001, 2005).

O empreendedor, assim como a organização — relação dialética —, posiciona-se dentro de múltiplos ambientes, que constituem diversos espaços sociais com os quais ele interage. Para concretizar seu projeto, o empreendedor exercita as suas convicções a fim de acessar os tipos de capitais que ele necessita para atender às suas aspirações. Nesse contexto, buscam-se alianças que proporcionem o aumento da disponibilidade de recursos para administrar os projetos organizacionais por parte dos atores que constituem seu ambiente (VERSTRAETE; JOUISON-LAFFITTE, 2007). No entanto, a relação existente entre os atores do ambiente e a díade é caracterizada pelo processo de trocas. Assim, para fornecer aos atores o que eles desejam, o empreendedor necessita instaurar uma configuração organizacional sobre a qual se apoiará.

Para se posicionar, o empreendedor organiza as disponibilidades a fim de fornecer, em seu espaço, um produto de troca e tentar abordar cada parte interessada com resultados satisfatórios. Essa organização corresponde à configuração da localização a fim de conceber os produtos ou serviços que são frutos das suas escolhas. A configuração de localização vai, assim, descobrir o empreendedor nas atividades de posicionamento e participar no fornecimento de resultados julgados satisfatórios para cada uma das partes interessadas. Incluem-se, assim, aspectos concernentes à política salarial, à política de marketing, à política 
Maria Christianni Coutinho Marçal, Sérgio C. Benício de Mello, José Roberto Ferreira Guerra \& Denis Dayvison Soares da Rocha

financeira, enfim, tudo o que diz respeito às estratégias funcionais e aos problemas de desenho organizacional (DESREUMAUX, 1992).

O conceito de auto-organização permite entender como uma organização pode se tornar autônoma num sistema mais amplo a sua volta - autoajuste do posicionamento, uma vez que, para existir, uma organização precisa estruturar ações no seu ambiente (LE MOIGNE, 1990). Por mais que a base conceitual do trabalho de Verstratete (2001) tenha completado mais de dez anos, a configuração teórica do seu modelo continua útil para o entendimento da atividade empreendedora conforme, atestado pelo estudo de Maranhão e Paiva Júnior (2008).

\section{Metodologia}

A presente pesquisa categoriza-se como qualitativa, pois se trata de um estudo que investiga um fenômeno social e que consiste em atos, atividades, significados, participação, relações e situações (TRIVIÑOS, 1995). A estratégia de pesquisa utilizada foi o estudo de caso, uma vez que se observou a análise intensiva de uma situação particular (TULL; HAWKINS, 1976) ou, ainda, a descrição de uma situação gerencial (BONOMA, 1985).

Por sua vez, o plano analítico compreendeu uma análise de conteúdo, que Bardin (1977) define como um conjunto de técnicas de análise das comunicações focadas numa investigação por meio de uma descrição objetiva, sistemática e quantitativa do conteúdo manifesto, com a finalidade de interpretar a mensagem. Seguindo as orientações da autora, a execução da análise constou dos seguintes passos: transcrição dos relatos do entrevistado, codificação dos conteúdos e posterior interpretação de seus significados à luz da teoria proposta e, por fim, levantamento estatístico.

A entrevista foi estruturada no sentido de indagar o entrevistado a respeito da realidade empreendedora, de sua vivência, visão futura do negócio, bem como características e arranjos funcionais. Dessa forma, a partir do mapa de codificação que foi gerado, a entrevista realizada foi analisada e, para cada trecho representativo das influências no processo de formação do empreendimento, foi atribuído um código de acordo com a adequação a determinada categoria (podendo uma frase obter mais de um código).

Após a codificação e ordenação de todos os dados (ver tabela 1), foi realizada uma análise de frequência representativa do número de vezes que determinado código foi mencionado nas entrevistas. As tabelas de frequência apresentadas na análise dos resultados incluem menções extraídas das entrevistas de acordo com o aparecimento e a relevância dos dados, que, por sua vez, foram também apresentados de forma percentual. 
A perspectiva dialógica no agir empreendedor: um estudo de caso em uma lan house

Tabela 1: Mapa de Codificação

\begin{tabular}{|c|c|c|}
\hline 1 & Dimensão cognitiva & $\begin{array}{l}\text { Visão do empreendedor, capacidades reflexivas } \\
\text { e de aprendizagem, efeitos das emoções, das } \\
\text { motivações, das experiências passadas e da } \\
\text { trajetória do indivíduo. }\end{array}$ \\
\hline 1.1 & Pensamento estratégico & $\begin{array}{l}\text { Ênfase na interação entre os esquemas de } \\
\text { interpretação do empreendedor e as suas ações. }\end{array}$ \\
\hline 1.2 & Reflexividade & $\begin{array}{l}\text { Habilidades do empreendedor de aprender e reagir } \\
\text { frente aos efeitos involuntários das ações. }\end{array}$ \\
\hline 1.3 & Aprendizagem & $\begin{array}{l}\text { Análise da influência das experiências passadas e } \\
\text { em curso, dos conhecimentos, das situações, das } \\
\text { paixões, das motivações, além das faculdades de } \\
\text { aprendizagem intrínsecas ao indivíduo sobre o } \\
\text { processo administrativo. }\end{array}$ \\
\hline 2 & Dimensão estrutural & $\begin{array}{l}\text { A estrutura constitui num dado momento um } \\
\text { arranjo particular que permite a um } \\
\text { observador ver as ordens e desordens inerentes } \\
\text { ao sistema no qual a díade está inserida. }\end{array}$ \\
\hline 2.1 & A estrutura objetiva & $\begin{array}{l}\text { Embora emane da gênese social, distancia-se } \\
\text { desta à medida que fatores como posição do } \\
\text { agente e grupos de capitais são considerados. }\end{array}$ \\
\hline 2.1 .1 & Posição do agente & $\begin{array}{l}\text { Análise do "papel" desempenhado na } \\
\text { organização. }\end{array}$ \\
\hline 2.1 .2 & Grupos de capitais & $\begin{array}{l}\text { Capital econômico (liquidez, bens possuídos, } \\
\text { etc.); capital cultural, que compreende o capital } \\
\text { cultural "incorporado" (hábitos), o capital cultural } \\
\text { "objetivo" (bens culturais possuídos, quadros, } \\
\text { abras literárias, etc.) e o capital cultural } \\
\text { "institucionalizado" (formas de tipos escolares). } \\
\text { Capital social (rede de relações); capital simbólico } \\
\text { (prestígio, reputação que é dada em uma área). }\end{array}$ \\
\hline 2.2 & A estrutura subjetiva & $\begin{array}{l}\text { Existência de um universo simbólico } \\
\text { compreendendo as convenções e as } \\
\text { representações sociais. }\end{array}$ \\
\hline 2.2 .1 & Convenções & Adesão às regras do meio/adaptação. \\
\hline 2.2 .2 & Representações sociais & Representações compartilhadas/socialização. \\
\hline 3 & $\begin{array}{c}\text { Dimensão } \\
\text { praxiológica }\end{array}$ & $\begin{array}{l}\text { A dimensão praxiológica constitui a essência da } \\
\text { materialização e da concretização do fenômeno } \\
\text { empreendedor. Dois tipos de ações servem ao } \\
\text { fenômeno empreendedor. }\end{array}$ \\
\hline 3.1 & Posicionamento & $\begin{array}{l}\text { Formação de alianças que proporcionem o } \\
\text { aumento da disponibilidade de recursos para } \\
\text { administrar os projetos organizacionais por parte } \\
\text { dos atores que constituem seu ambiente. }\end{array}$ \\
\hline 3.2 & $\begin{array}{l}\text { Localização de uma } \\
\text { configuração }\end{array}$ & $\begin{array}{l}\text { A empresa reflete seu posicionamento assumindo } \\
\text { uma configuração que seja satisfatória para cada } \\
\text { uma das partes interessadas. }\end{array}$ \\
\hline
\end{tabular}

REAd I Porto Alegre - Edição 73 - Nº 3 - set/dez 2012 - p. 813-828 
Maria Christianni Coutinho Marçal, Sérgio C. Benício de Mello, José Roberto Ferreira Guerra \& Denis Dayvison Soares da Rocha

Fonte: os autores

\section{Análise dos dados}

Embasando-se na análise das afirmativas que o sujeito da pesquisa emitiu, de forma generalizada, pôde-se perceber uma ênfase maior na dimensão estrutural; mais especificamente na estrutura objetiva $(86,54 \%)$, na qual podemos destacar a posição do agente e o grupo de capitais que ele constrói ao desempenhar suas atividades.

Na dimensão cognitiva, a variável aprendizagem foi a que teve uma maior frequência (76,92\%), aludindo-nos à importância fundamental que esta desempenha no processo de empreender (vide Tabela 2), assim como debatido no estudo de Julien (2010). Fatos como história de vida, emoções e experiência estão atrelados ao seu ato de empreender, como aponta o extrato da entrevista:

"Sou daqueles que... sempre tive Atari..." Essa afirmativa também denota aspectos relevantes em relação às outras duas dimensões, pois como não dizer que esse fato aprendido por ele, ao ter sido jogador, esteve intrinsecamente ligado à escolha que ele fez do tipo de negócio, da sua ação e também do posicionamento estratégico adotado, que refletirá em sua prática? Esse questionamento vai ao encontro dos achados do estudo de Paiva Jr., Almeida e Guerra (2008) no que concerne o entendimento dos autores sobre a ação do empreendedor humanizado que busca encontrar meios e oportunidades de diálogo entre o desenvolvimento do seu empreendimento e a sua trajetória de vida. A afirmativa aproxima-se também ao que Verstraete e Jouison-laffitte (2012) definem como uma forma de se encontrar uma ideia para o desenvolvimento de negócio - a experiência pessoal.

Tabela 2: Frequências totais das dimensões em relação aos 52 estratos

\begin{tabular}{|l|l|c|c|}
\hline \multicolumn{3}{|c|}{$\begin{array}{c}\text { Freq. total } \\
\text { Cód. }\end{array}$ Conceito } \\
\cline { 4 - 4 } $\mathbf{1}$ & Dimensão cognitiva & & \% \\
\hline $\mathbf{1 . 1}$ & Pensamento estratégico & $\mathbf{3 8}$ & $\mathbf{7 3 , 0 8}$ \\
\hline $\mathbf{1 . 2}$ & Reflexividade & $\mathbf{3 0}$ & $\mathbf{5 7 , 6 9}$ \\
\hline $\mathbf{1 . 3}$ & Aprendizagem & $\mathbf{4 0}$ & $\mathbf{7 6 , 9 2}$ \\
\hline $\mathbf{2}$ & Dimensão estrutural & & \\
\hline $\mathbf{2 . 1}$ & A estrutura objetiva & $\mathbf{4 5}$ & $\mathbf{8 6 , 5 4}$ \\
\hline $\mathbf{2 . 1 . 1}$ & Posição do agente & $\mathbf{4 5}$ & $\mathbf{8 6 , 5 4}$ \\
\hline $\mathbf{2 . 1 . 2}$ & Grupos de capitais & & \\
\hline $\mathbf{2 . 2}$ & A estrutura subjetiva & $\mathbf{4 1}$ & $\mathbf{7 8 , 8 5}$ \\
\hline $\mathbf{2 . 2 . 1}$ & Convenções & $\mathbf{4 3}$ & $\mathbf{8 2 , 6 9}$ \\
\hline $\mathbf{2 . 2 . 2}$ & Representações sociais & & \\
\hline $\mathbf{3}$ & Dimensão praxiológica & $\mathbf{3 7}$ & $\mathbf{7 1 , 1 5}$ \\
\hline $\mathbf{3 . 1}$ & Posicionamento & $\mathbf{3 7}$ & $\mathbf{7 1 , 1 5}$ \\
\hline $\mathbf{3 . 2}$ & Localização de uma configuração & & \\
\hline
\end{tabular}

Fonte: os autores

Segundo Verstraete $(2001,2005)$, as variáveis que aparecem dentro das dimensões tendem a não surgir de forma isolada, o que foi corroborado com a prática, quando, na fala do nosso empreendedor, pudemos observar que, nas questões alusivas à dimensão cognitiva, apenas $25 \%$ remetiam a apenas uma componente. Ou seja, observa-se uma forte relação entre as componentes da dimensão cognitiva, tanto pela baixa frequência com que estas ocorrem isoladamente quanto pelas significantes frequências com que são visualizadas em interação

REAd I Porto Alegre - Edição 73 - Nº 3 - set/dez 2012 - p. 813-828 
A perspectiva dialógica no agir empreendedor: um estudo de caso em uma lan house

(pelo menos duas ou três) (vide Tabela 3). Quando o empreendedor fala: "Abri a minha loja, depois fui convidado por ' $\mathrm{x}$ ' para ser sócio".

Aspectos alusivos às três componentes cognitivas estão presentes, assim como componentes das dimensões estrutural e praxiológica. Outro exemplo das três dimensões presentes numa mesma ação está contido na passagem abaixo:

"A primeira experiência que tive como dono de negócio foi a agência e segundo eu entrei em lan house. Mas aqui eu já (estava) tentando vender equipamento, virar também assistência técnica. Eu já to me preparando para isso."

Tabela 3: Frequências com que as componentes da dimensão cognitiva ocorrem associadas

\begin{tabular}{|l|c|c|}
\hline Número de componentes envolvidas & Freq. & $\mathbf{\%}$ \\
\hline As três componentes & $\mathbf{2 1}$ & $\mathbf{4 0 , 3 8}$ \\
\hline Pelo menos duas componentes & $\mathbf{3 9}$ & $\mathbf{7 5}$ \\
\hline Apenas uma componente & $\mathbf{1 3}$ & $\mathbf{2 5}$ \\
\hline
\end{tabular}

Fonte: os autores

As variáveis posição do agente e grupos de capitais que o mesmo constrói ao executar suas atividades influenciam de forma associada na estrutura objetiva em $75 \%$ das falas (vide Tabela 4). Na estrutura subjetiva, o mesmo fenômeno ocorreu; ou seja, as dimensões analisadas surgiram de forma associada em $73 \%$ das falas do entrevistado (vide Tabela 5). Aspectos alusivos à dimensão estrutural (em suas duas componentes: estrutura subjetiva e objetiva) podem ser observados nos seguintes estratos: "É, mas eu queria ter mais capital. Queria ter mais coragem para arriscar, tá [sic.] entendendo? Mas já foi uma ajuda. Eu só tenho que agradecer a minha mãe, a meu pai”. Aspectos alusivos à dimensão cognitiva (reflexividade) também podem ser encontrados na supracitada assertiva do entrevistado.

Tabela 4: Frequências com que as componentes da estrutura objetiva da dimensão estrutural ocorrem associadas

\begin{tabular}{|l|l|l|}
\hline Número de componentes envolvidas & Freq. & $\%$ \\
\hline Associadas & 39 & 75 \\
\hline Isoladamente & 12 & 23 \\
\hline Não aparecem & 07 & 12,4 \\
\hline
\end{tabular}

Fonte: os autores

Tabela 5: Frequências com que as componentes da estrutura subjetiva da dimensão estrutural ocorrem associadas

\begin{tabular}{|l|l|l|}
\hline Número de componentes envolvidas & Freq. & \% \\
\hline Associadas & 38 & 73 \\
\hline Isoladamente & 08 & 15,4 \\
\hline Não aparecem & 12 & 23 \\
\hline
\end{tabular}

Fonte: os autores

Na dimensão praxiológica, que nos remete ao posicionamento e à configuração adotada pelo empreendedor em suas práticas, o imbricamento das suas componentes surgiu de

REAd I Porto Alegre - Edição 73 - Nº 3 - set/dez 2012 - p. 813-828 
Maria Christianni Coutinho Marçal, Sérgio C. Benício de Mello, José Roberto Ferreira Guerra \& Denis Dayvison Soares da Rocha

forma mais evidente, podendo-se visualizar por meio da frequência nula em sua forma isolada (vide Tabela 6), corroborando os achados do estudo de Bruyat e Julien (2001) e dos estudos de Verstraete $(2001,2005)$. A configuração do seu negócio através da mobilização de pessoas e também o reflexo do seu posicionamento podem ser observados nas passagens abaixo, além das outras duas dimensões do modelo (cognitiva e estrutural), quando ele respondeu à seguinte questão: Como é que você percebe que tem de fazer alguma ação diferenciada?

"A gente tem um banco de dados, aí a gente fica acompanhando o movimento de tempo por máquina aí, a gente faz um comparativo disso com o ano passado, com o outro ano, com outro ano... E aí vendo, a gente tem uma ideia de quanto vai dar no mês. Às vezes a gente erra, um ou dois meses, mas assim a gente vê que esse mês não vai ta [sic.] bom."

"Primeiro, tenta ver o que é. Se é alguma loja concorrente que está com um preço absurdo. Primeiro saber se é isso aí. Depois, eu converso com o cliente para saber o que tá acontecendo. Porque tem algumas coisas, tipo o carnaval, que influi. Não tem como você ter uma certeza, só uma ideia por alto. Tipo assim, semana de prova não sei aonde [sic.], semana de prova de faculdade. Eu procuro saber o porquê disso. E, às vezes, quando não é nada relacionado a isso, cai a mais de que isso, aí eu procuro realmente uma panfletagem. Já fiz rádio, já fiz outdoor. Aí eu procuro alguma coisa."

Tabela 6: Frequências com que as componentes da dimensão praxiológica ocorrem associadas

\begin{tabular}{|l|c|c|}
\hline Número de componentes envolvidas & Freq. & $\mathbf{\%}$ \\
\hline Associadas & 37 & 71,1 \\
\hline Isoladamente & 0 & 0 \\
\hline Não aparecem & 15 & 28,9 \\
\hline
\end{tabular}

Fonte: os autores

\section{Considerações Finais}

Os dados obtidos ilustram a alta correlação entre as três dimensões apresentadas por Verstraete $(2001,2005)$, sendo alta a frequência com que ocorrem associadas e nula a existência delas isoladamente. Além disso, a presença das dimensões em todos os 52 extratos nos leva a inferir que o modelo está em forte sintonia com o fenômeno empreendedor, constituindo-se, com isso, como importante subsídio ao entendimento da realidade do fenômeno do empreendedorismo como multidisciplinar e dialógico, conforme a teoria que Verstraete vem desenvolvendo nos estudos apresentados neste artigo.

Se, por um lado, a total indissociabilidade das dimensões não foi evidenciada em todos os estratos (apenas em 67,31\% deles), a análise geral em relação à alta frequência com que as dimensões foram mencionadas no conjunto maior evidencia que estes estão fortemente imbricados no fenômeno em análise (vide Tabela 7).

Tabela 7: Frequências com que as dimensões são evidenciadas associadas

\begin{tabular}{|c|c|c|}
\hline Número de componentes envolvidas & Freq. & $\mathbf{\%}$ \\
\hline As três dimensões & $\mathbf{3 5}$ & $\mathbf{6 7 , 3 1}$ \\
\hline Pelo menos duas dimensões & $\mathbf{3 7}$ & $\mathbf{7 1 , 1 5}$ \\
\hline Apenas uma dimensão & $\mathbf{0}$ & $\mathbf{0}$ \\
\hline
\end{tabular}

REAd I Porto Alegre - Edição 73 - N 3 - set/dez 2012 - p. 813-828 
A perspectiva dialógica no agir empreendedor: um estudo de caso em uma lan house

\begin{tabular}{|c|c|c|}
\hline Não aparecem & $\mathbf{0}$ & $\mathbf{0}$ \\
\hline Fonte: os autores
\end{tabular}

Tabela 8: Frequências com que as dimensões são evidenciadas em pelo menos uma de suas componentes

\begin{tabular}{|l|c|c|}
\hline Número de componentes envolvidas & Freq. & $\%$ \\
\hline Dimensão cognitiva & 51 & 98,08 \\
\hline Dimensão estrutural & 52 & 100 \\
\hline Dimensão Praxiológica & 36 & 69,23 \\
\hline
\end{tabular}

Fonte: os autores

\section{Implicações Gerenciais}

O modelo dialógico e multidisciplinar em estudo fornece caminhos, através da análise das suas dimensões, que podem elucidar práticas empreendedoras mais conscientes e um aporte teórico que propicia uma reflexão mais abrangente. A importância da compreensão do entrelaçamento existente na díade empreendedor-empreendimento, que formam o fenômeno do empreendedorismo, pode despertar no gestor uma maior preocupação a respeito da interface existente entre a díade e o ambiente no qual está imerso, ou seja, suas redes e formas de relacionamento.

Embora o modelo não implique uma nova forma de gerenciar, este oferece importantes subsídios ao entendimento da realidade organizacional (e.g. na ação de definição de planejamentos estratégico, tático e operacional), aproximando a administração do empreendedorismo, quando este aparece como tema transversal, proporcionando, assim, uma visão dinâmica e integrada do fenômeno em questão. Em um estudo atual, Verstraete propõe essa integração por meio de uma reflexão que aproxima o empreendedorismo do plano de negócios (VERSTRAETE; JOUISON-LAFFITTE, 2012). A relevância do estudo reside na ampliação de perspectivas na área de empreendedorismo, ao contribuir com o campo disciplinar fornecendo subsídios teóricos para analisar tal fenômeno à luz de uma abordagem dialógica, que não tem sido comumente empregada nos estudos da área ao longo da última década.

Com efeito, no estudo que tomamos como base para este artigo, o ator trata de fundamentar seu êxito sobre o que ele percebe, consciente ou inconscientemente, para utilização de métodos mais ou menos formais de análise estratégica, como fator de evolução, engajando-se em ações que permitem concretizar e dominar as supracitadas áreas da realidade organizacional (VERSTRAETE, 2001).

Por fim, pode-se clarificar que o caráter multidisciplinar e multifacetado revelado sob o prisma do modelo proporciona ao empreendedor uma ampliação dos seus pressupostos cognitivos no que tange à formulação de estratégia, ao pensamento sobre a ação e à aprendizagem. Nesse sentido, estabelece-se uma conversação com a dimensão praxiológica, e, com isso, o empreendedor pode acessar ou desenvolver práticas organizacionais dialógicas que permitem ampliar sua capacidade de reflexão sobre a própria ação.

\section{REFERÊNCIAS}

ABRAGAMES. Plano diretor anual, 2005. Disponível em: $<$ http://www.abragames.com.br/>. Acesso em: 10 out. 2005.

REAd I Porto Alegre - Edição 73 - Nº 3 - set/dez 2012 - p. 813-828 
Maria Christianni Coutinho Marçal, Sérgio C. Benício de Mello, José Roberto Ferreira Guerra \& Denis Dayvison Soares da Rocha

ABRAGAMES. A indústria brasileira de jogos eletrônicos: um mapeamento do crescimento do setor nos últimos 4 anos. Pesquisa 2008, versão 1.0. Disponível em: <http://www.abragames.com.br/>. Acesso em: 05 jan. 2012.

ABREU, A. Videogame: um bem ou um mal? Um breve panorama da influência dos jogos eletrônicos na cultura individual e coletiva. 2003. Disponível em:

$<$ http://andredeabreu.com.br/docs/videogames_bem_ou_mal.pdf>. Acesso: 27 fev. 2006.

ABRIC, J. C. Pratiques et représentations sociales. Paris: Presses Universitaires de France, 1994.

ARGYRIS, C.; SCHÖN D. A. Aprendizagem Organizacional. Massachussetts: Addison Wesley, 1988.

BARDIN, L. Análise de conteúdo. Lisboa: Edições 70, 1977.

BAUDRILLARD, J. O sistema dos objetos. 4. ed. São Paulo: Perspectiva, 2004.

A sociedade de consumo. Lisboa: Edições 70, 1995.

BERGER, P.; LUCKMAN, T. A Construção social da realidade: tratado de sociologia do conhecimento. Petrópolis: 4. ed. Vozes, 1978.

BLACKWELL, R. D.; ENGELS, J. F. Comportamento do Consumidor. 8. ed. Rio de Janeiro: Ltc, 2000.

BONOMA, T. V. Case research in Marketing: opportunities, problems and process. Journal of Marketing Research, vol. 22, may. 1985.

BOURDIEU, P. Coisas Ditas. São Paulo: Brasiliense, 2004.

BRUYAT, C.; JULIEN, P. A. Defining the field of research in entrepreneurship. Journal of Business Venturing, v. 16, n. 2, p-165-180, 2001.

CASTELLS, M. A sociedade em rede. 3. ed. São Paulo: Paz e Terra, 1999.

A galáxia da internet: reflexões sobre a Internet, os negócios e a sociedade. Rio de Janeiro: Jorge Zahar Ed., 2003.

DESREUMAUX, A. Structures d'enterprise. Paris: Vuibert, 1992. 
A perspectiva dialógica no agir empreendedor: um estudo de caso em uma lan house

DOISE, W.; PALMONARI, A. L'étude dês représentations sociales. Paris: Delachaux \& Niestlé, 1986.

ESCOBAR, A. Welcome to cyberculture: notes on the antropology of cyberculture. Current Anthropology, v. 35, p. 211-231, 1994.

FILION, L. J. Diferenças entre sistemas gerenciais de empreendedores e operadores de pequenos negócios. Revista de Administração de Empresas, São Paulo, v. 39, n. 4, p. 6-20, out./dez. 1999.

GIBSON, W. Neuromancer. 3. ed. São Paulo: Aleph, 2003.

GUIMARÃES JR, M. A cibercultura e o surgimento de novas formas de sociabilidade. Trabalho apresentado no GT "Nuevos mapas culturales: cyber espacio y tecnologia de la virtualidad”, na II Reunión de Antropologia Del Mercosur, Piriápolis, Uruguai, de 11 a 14 de novembro de 1997. Disponível em: <http://www.cfh.ufsc.br/ guima/ciber.html>. Acesso em: 10 dez. 2005.

GUIMELLI, C. (ed.). Structures et transformations dês représentations sociales. Paris: Delachaux \& Niestlé, 1994.

GOMEZ, P. Y. Qualité et théorie dês conventions. Paris: Económica, 1994.

JODELET, D. Lês représentations sociales. Paris: Presses Universitaires de France, 1989.

JULIEN, P. A. Empreendedorismo Regional e Economia do Conhecimento. São Paulo: Saraiva, 2010.

LÊ MOIGNE, J. L. La modélisation dês systèmes complexes. Paris: Dunod, 1990.

LÉVY, P. O que é o virtual? São Paulo: Ed. 34, 1996.

MARANHÃO, C. R. O.; PAIVA JÚNIOR, F. G. Empreendendo no turismo: uma análise do comportamento empreendedor dos dirigentes das agências de viagens brasileiras ante a nova economia. Observatório de Inovação do Turismo - Revista Acadêmica, v. 3, n. 2, p. 1-17, jun. 2008.

OGBOR, J. Mythcizing and Reification in Entrepreneurial discourse: Ideology-critique of entrepreneurial studies. Journal of Management Studies, v. 37, n. 5, p. 605-635, jul. 2000. 
Maria Christianni Coutinho Marçal, Sérgio C. Benício de Mello, José Roberto Ferreira Guerra \& Denis Dayvison Soares da Rocha

ORLEAN, A. (org). Analyse économique dês conventions. Paris: Presses Universitaires de France, 1994.

PAILOT, P. La mémoire en héritage: éléments d'analyse socio-psychique de la socialisation entrepreneuriale anticipée. In: Ve Congrés International Francophone sur la PME, 2000. Disponível em: <http://www.airepme.univ-metz.fr>. Acesso em: 24 mar. 2006.

PAIVA JR.; F. G.; ALMEIDA, S. L.; GUERRA, J. R. F. O Empreendedor Humanizado como uma Alternativa ao Empresário Bem-sucedido: um novo conceito de empreendedorismo, inspirado no filme Beleza Americana. RAM - Revista de Administração Mackenzie, v. 9, p. 112-134, 2008.

PREVIDELLI, J. J.; MEURER, V.; PREVIDELLI, I. T. S. Estudo da causa mortis de micros e pequenas empresas brasileiras. Ciudad de México, México: XXXVI Asamblea Anual del Cladea, 2001.

RIBEIRO, I. Os games agora são obras de arte. Veja especial Natal Digital. Ano 38. Editora Abril. Novembro de 2005. Edição Especial n. 52. 87 páginas.

ROUANET, S. P. As Razões do Iluminismo. 4. ed. São Paulo: Companhia das Letras, 1987.

SALAIS, R. Incertitudes et interactions de travail: dês produits aux conventions. In: ORLÉAN A. (Dir). Analyse économique dês conventions. Paris: Presses Universitaires de France, 1994.

TRIVIÑOS, A. Introdução à pesquisa em ciências sociais: a pesquisa qualitativa em educação. 4. ed. São Paulo: Atlas, 1995.

TULL, D. S.; HAWKINS, D. I. Marketing research, meaning, measurement and method. London: Macmillan Publishing, 1976.

VELHO, G. Projeto e metamorfose: a antropologia das sociedades complexas. Rio de Janeiro: Jorge Zahar, 1994.

VERSTRAETE, T. Dialectic modelling of the entrepreneurial phenomenon: a french point of view. Les Cahiers de la Recherche: Lille, 2000.

VERSTRAETE, T. Entrepreneuriat: modélisation du phénomène. Reveu de l'Entrpreneuriat, v. 1, n. 1., p. 5-24, 2001. 
A perspectiva dialógica no agir empreendedor: um estudo de caso em uma lan house

VERSTRAETE, T. Essay on the singularity of entrepreneurship as a research domain. Les Éditions de l'ADREG, 2002. (www.editions-adreg.net).

VERSTRAETE, T. Proposal for a theoretical framework for research in entrepreneurship: $\mathrm{EPh}=\mathrm{f}[(\mathrm{CxSxP}) \mathrm{c}(\mathrm{ExO})]$. Les Éditions de l'ADREG, 2005. (www.editions-adreg.net).

VERSTRAETE, T.; FAYOLLE, A. Paradigmes et entrepreneuriat. Revue de l'Entrepreneuriat, v.4, n.1, p. 33-52, 2005.

VERSTRAETE, T.; JOUISON-LAFFITTE, E. Three theories to frame the concept of BM in context of firm foundation, paper presented at the International Council of Small Business, 52nd World conference, Turku, Finland, p.13-15, Junho, 2007.

VERSTRAETE, T.; JOUISON-LAFFITTE, E. Une théorie conventionnaliste du business model en contexte de création d'entreprise pour comprrendre l'impulsion organisationelle. Management International. v.15, n. 2, p.109-124, 2010.

VERSTRAETE, T.; JOUISON-LAFFITTE, E. A business model for entrepreneurship. Northampton: Edward Elgar Publishing, 2012.

WEICK, K. E. The social psychology of organizing. Massachussetts: Addison-Westley, 1979. 